\title{
Sistemas Adaptativos Complexos e Relações Professor-Aluno no Contexto Idiomas sem Fronteiras ${ }^{1}$ Complex Adaptive Systems and Teacher-Student Connection on a Language without Borders Context
}

\author{
Semírames Bruna ÁVILA* \\ Gasperim Ramalho de SOUZA**
}

\begin{abstract}
RESUMO: O objetivo deste artigo é explorar a ideia de sistemas complexos na Linguística Aplicada e sua relevância dentro do ambiente de salas de aula do Núcleo de Línguas do Idiomas sem Fronteiras da Universidade Federal de Lavras. O conceito de sistemas complexos não é um conceito original das ciências da linguagem, mas herdado das ciências exatas. Essa ideia representa um dinamismo formado por diversos elementos, que, unidos, formam um sistema dinâmico e interativo. Em um contexto educacional, isso também ocorre, sendo que entre esses elementos se encontra a interação professor-aluno. Dessa forma, refletimos como a bagagem cultural, as experiências de vida e as personalidades podem afetar o fenômeno do ensino-aprendizagem. Para analisar tais aspectos, montamos um roteiro de entrevista e aplicamos para alguns alunos que se voluntariaram, com o objetivo de descobrir como as relações no ambiente educacional influenciam o processo ensino-aprendizagem. Buscamos, assim, por meio desta perspectiva, aproximarmos teoria e realidade, exemplificando como uma relação mais próxima entre professor e aluno atua positivamente no aprendizado e, por essa razão, é preciso questionar e repensar as relações dentro de um ambiente educacional.
\end{abstract}

PALAVRAS-CHAVE: Sistemas adaptativos complexos; Sala de aula; Relação professoraluno.

\begin{abstract}
The aim of this paper is to explore the idea of complex systems in Applied Linguistics and their relevance within the NucLi / IsF (Language Without Borders) classroom environment of DRI / Federal University of Lavras. The concept of complex systems is not rooted in the language sciences, but it was inherited from the exact sciences. This idea represents a dynamism formed by several elements, which together form a dynamic and interactive system. In an educational context, this also occurs, and among these elements there is the teacher-student interaction. In this way, we reflect how cultural background, life experiences and personalities can affect the phenomenon of teaching-learning. In order to analyze these aspects, we set up an interview script and applied it on some students who volunteered, with the purpose of finding out how the relations in the educational environment influence the teaching-learning process. Thus, through this perspective, we seek to approach theory and reality, exemplifying how a closer relationship between teacher and student acts positively in learning and, for this reason, it is necessary to question and rethink relationships within an educational environment.
\end{abstract}

KEYWORDS: Complex adaptive systems; Classroom; Teacher-student connection.

\footnotetext{
${ }^{1}$ Agradecemos a Marllon Rosa e à Prof. Jamila Viegas pelas discussões que também subsidiaram a escrita deste artigo.

* Graduanda em Letras Português/Inglês pela UFLA - semiramesavila18@gmail.com

${ }^{* *}$ Doutorando pelo CEFET-MG, Professor Assistente da UFLA - gasperim.souza@ufla.br
} 


\title{
1 Introdução
}

O Programa Idiomas sem Fronteiras (IsF) é fruto de uma parceria entre o Ministério da Educação (MEC/SESu) e a Coordenação de Aperfeiçoamento de Pessoal de Nível Superior (CAPES), visando atender a universidades federais e estaduais ao ofertar cursos de línguas gratuitos para alunos, professores, técnicos administrativos e terceirizados. Essa ação objetiva o desenvolvimento de uma política linguística a favor da internacionalização do ensino superior no Brasil. Por questões de recorte, a presente pesquisa foi desenvolvida no Núcleo de Línguas do IsF, localizado na Universidade Federal de Lavras em Minas Gerais.

No presente trabalho fora abordada a Teoria da Complexidade, que também advém da Teoria Geral de Sistemas. A respeito do momento dessa constituição teórica, Rios Neto (2008, p.01) afirma que:

\begin{abstract}
por volta da década de 60 , houve a quarta revolução iniciada por cientistas de diversas áreas como Edward Lorenz, Benoit Mandelbrot, René Thom, Henry Atlan, Lotfi Zadeh, Ilya Prigogine, Humberto Maturana, Francisco Varela e Edgar Morin, os quais começaram a desenvolver vários estudos apoiados nestas novas descobertas, originando as teorias da complexidade: teoria do caos, autopoiese, teoria dos fractais, auto-organização, estruturas dissipativas, teoria das catástrofes, lógica fuzzy, e outras. Em decorrência destas novas descobertas da ciência, passou-se a disseminar no meio científico o denominado pensamento complexo.
\end{abstract}

Partindo dessa premissa, para Morin (2007), complexidade é não necessariamente algo complicado. Para o autor, o sentido da palavra complexo se refere ao que "não pode se resumir numa palavra chave, o que não pode ser reduzido a uma lei nem a uma ideia simples [...] a complexidade se apresenta com os traços inquietantes do emaranhado, do inextricável, da desordem, da ambiguidade, da incerteza [...](2007, p.05)". Nesse sentido, a complexidade se dá através das partes que compõem um todo e suas interações.

Por esse ângulo, Van Lier (1996) traz que os espaços educativos são Sistemas Adaptativos Complexos, ou seja, sistemas com múltiplos elementos em constante mudança e em fluxo inesperado. Tal aspecto descreve tanto a sala de aula como o cérebro do aluno, sobretudo em um contexto de ensino de línguas (CAMERON e LARSEN-FREEMAN, 2007). Uma das variáveis dessa vertente teórica é o ambiente escolar, cuja descrição durante anos é feita como um lugar em que a educação ocorre de maneira difícil e complicada. 
Dessa maneira, vemos que uma sala de aula é muito mais do que somente aluno e professor; o lugar está sempre sujeito a mudanças. Lima $(2017$, p. 03) traz que "a educação nem sempre é tranquila e, muitas e muitas vezes, é na verdade conflituosa”, assim mostrando a imprevisibilidade presente nesse sistema adaptativo que é a escola (e a própria sala de aula). Essa imprevisibilidade pode ser ilustrada pelas diversas situações que ocorrem dentro da sala de aula, a saber, a forma como os alunos se sentam, os assuntos que eles desenvolvem através ou paralelamente à aula, a interpretação das linguagens gestuais do professor, colegas, a reação diante de uma atividade proposta, assim como a interação proposta pelo professor para a execução dessa atividade (individualmente, em dupla e em grupos). Cada elemento desses, individualmente ou em agregados em um "todo" podem gerar turbulências ou conflitos nesse sistema adaptativo.

Corroborando o que foi dito anteriormente, Van Velzen (1985) afirma que uma mudança em sala de aula assente em três variáveis: (I) o âmbito que está relacionado com a amplitude da mudança (II) a dimensão que está associada à complexidade relativa da mudança e (III) o grau que está associado ao nível educacional em que essa mudança ocorre. Vemos então a complexidade por trás de uma transformação, sendo impossível antecipar os possíveis acontecimentos no ambiente escolar. Em suma, essas variáveis convergem no sentido de se compreender a intensidade como os alunos podem sentir e reagir a uma mudança por parte das escolhas feitas pelo professor (ou pela ação dos colegas).

Retomando a teoria base deste artigo, entende-se que a dinâmica dos sistemas complexos está ligada aos elementos constituintes que envolvem os participantes em determinada situação, como as emoções de todas partes, o contexto socioeconômico, a responsabilidade, a ética, as condições do ambiente em que vivem e em que convivem. Como esses fatores estão em contínua alteração, afetam as relações entre eles e, por consequência, o sistema. Além disso, o sistema também apresenta uma abertura para elementos externos. Tais fatores acabam gerando uma não-linearidade, já que não há uma relação proporcional entre causa e efeito. É importante, no entanto, apontar que o ambiente ou contexto no qual o sistema se encontra não é externo a ele, mas parte constituinte do mesmo (CAMERON e LARSEN-FREEMAN, 2007).

A ideia de sistemas complexos no contexto do ensino de línguas afeta como os conteúdos são abordados, pois ao considerarmos a língua dentro de um sistema 
imprevisível e mutável, certas concepções acabam por serem questionadas. Nesse sentido, a sala de aula enquanto ambiente complexo também possui seus próprios elementos. Aqui destacamos, entre eles, sobretudo, o papel do professor e a organização física da sala de aula.

Objetiva-se, a partir disso, compreender como os elementos supracitados afetam o processo ensino-aprendizagem. Levamos em consideração aqui, sobretudo, a percepção dos alunos. Vemos os alunos como parte essencial de tal processo e acreditamos que seu olhar pode oferecer importantes contribuições para a melhoria da prática docente. Desta forma, levantamos, por meio de questionários, ponderações acerca do ambiente educacional do NucLi/IsF em comparação a experiências prévias por parte dos entrevistados em situações de aula de língua inglesa.

\section{O Sistema Complexo em Sala de Aula}

A sala de aula é um sistema adaptativo complexo composto de seres animados e inanimados que pode alterar o caminho planejado a qualquer momento.

A sala de aula pode ser vista como uma comunidade reunida para atingir um determinado objetivo, que deve ser compartilhado por todos, com divisão de responsabilidades entre os membros dessa comunidade, alunos e professor, cada um se compromissando com o papel que the cabe (LEFFA, 2016, p.07).

Partindo desse conceito e levando em consideração os elementos desse sistema complexo, discutiremos sobre dois conceitos específicos e de extrema importância: as relações humanas (professor/aluno e aluno/aluno) e a organização do espaço físico; ambas igualmente relevantes e sujeitas à mutação.

\subsection{Relação professor-aluno e Relação aluno-aluno}

Uma das principais dificuldades em se descrever um professor está no fato de que professores utilizam métodos completamente diferentes. Freire traz que "o aprendizado do ensinante ao ensinar se verifica à medida em que o ensinante, humilde, aberto, se ache permanentemente disponível a repensar o pensado, rever-se em suas posições [...]" (FREIRE, 2001) e esse pensamento relaciona-se à Teoria da Complexidade, quando pensamos no protagonismo do aluno e sua valorização nesse meio adaptativo complexo; momento em que o professor deixa de ser o centro das atenções e se coloca como elemento adaptativo de um sistema. 
Harmer (2007) aponta ainda que a personalidade do professor é formada a partir de dois aspectos: (I) quem o sujeito realmente é e (II) como o sujeito se apresenta enquanto professor. Ele indica, no entanto, que não se trata de seguir um estereótipo previamente formado, mas criar uma figura que ele quer que o aluno tenha dele. Um professor deve ser capaz de se adaptar e reagir aos diversos acontecimentos que possam ocorrer em sala de aula. Uma turma é diferente da outra e pessoas sempre reagirão de modos diferentes ao mesmo conteúdo. Considerando o ambiente complexo e a imprevisibilidade de tais eventos, o professor deve estar preparado para flexibilizar-se naquele ambiente.

Partindo dessa premissa, é possível afirmar que a sala de aula abarca relações complexas, pois dentro deste ambiente existem múltiplas identidades interagindo entre si e com o espaço físico. Nesse sentido, Mandelbrot (1982) coloca que existe uma relação dialética entre o todo e suas partes. Em outras palavras, o autor propôs que tudo que existe no universo ainda que observado microscopicamente é uma pequena parte que reflete as características de um todo. A exemplo disso, podemos pensar no DNA que está dentro das células (parte de um todo) e através dele sabemos características externas de um indivíduo (o todo) tais como a cor do olhos, cabelos, cor da pele etc.

Embora essa inter-relação entre o todo e suas partes tenha fundamentado o modelo dos fractais criado por Mandelbrot (muito popular entre os matemáticos e físicos), ela serve de base hoje, na linguística, para pensarmos que a identidade dos nossos alunos é multifacetada ou seja , na sala de aula temos uma amostra ( parte) de uma identidade ("um todo") que não pode ser compreendida sem pensarmos nos nossos alunos como sujeitos que possuem gênero, sexualidade, raça, condição social e econômica, dentre outros aspectos constituintes daquele todo.

Dessa maneira, Sade (2008) traz que o indivíduo é construído através de vários outros, e o entendimento dessas interações como aspecto importante do comportamento do sujeito, permite afirmar que somos sistemas complexos, uma vez que cada parte e a interação corroboram para a formação do ser. Por esse ângulo, a efetividade do processo de ensino-aprendizagem depende, essencialmente, do ambiente em que a aula é desenvolvida e da relação que o professor constrói com seus estudantes. Logo, uma boa relação entre professores e alunos, bem como entre os próprios alunos, pode ser construída a partir da percepção e sensibilidade diante das subjetividades, diferenças e potencialidades que cada indivíduo apresenta enquanto parte de um sistema complexo. 


\subsection{A Organização Física da Sala de Aula}

A sala de aula é um espaço onde os alunos devem se sentir seguros e confortáveis para dar suas opiniões. Todos os elementos que compõem esse ambiente são decisivos na hora do aprendizado. Dentro de uma sala de aula, para além do professor, temos diferentes variáveis que podem influenciar no aprendizado, tais como o perfil dos alunos, a estrutura física, o contexto sócio-político-econômico-cultural local, e até a disposição das carteiras em sala.

O modelo tradicional utilizado na maioria das salas de aula ainda é o de filas com o professor à frente como foco total do processo. No entanto, tal disposição não favorece a construção do conhecimento.

Harmer (2007) fala das diferentes possibilidades de disposição do ambiente que possibilitam uma melhor interação aluno-aluno e professor-aluno. Segundo ele, a disposição de carteiras em fila possibilita o trabalho individual e é indicado para aulas nas quais será explicado gramática ou feita a transmissão de um vídeo. No entanto, no geral, a maioria das salas de aula possibilita a moção das mesas dos alunos de modo a adequá-las à atividade proposta pelo professor, sendo possível montar: grupos de quatro ou cinco pessoas, onde se pode explorar discussões em pequenos grupos onde o professor media as interações; formação de meia lua (popularmente também conhecida como ferradura) que possibilita uma discussão conjunta e que coloca o professor na posição dos alunos; formato de círculo, que proporciona ao professor a oportunidade de se sentar com os alunos e deixálos mais confortáveis, já que o professor passa a ser visto com maior igualdade, entre outros.

Figura 1- Exemplos de disposições em sala de aula.

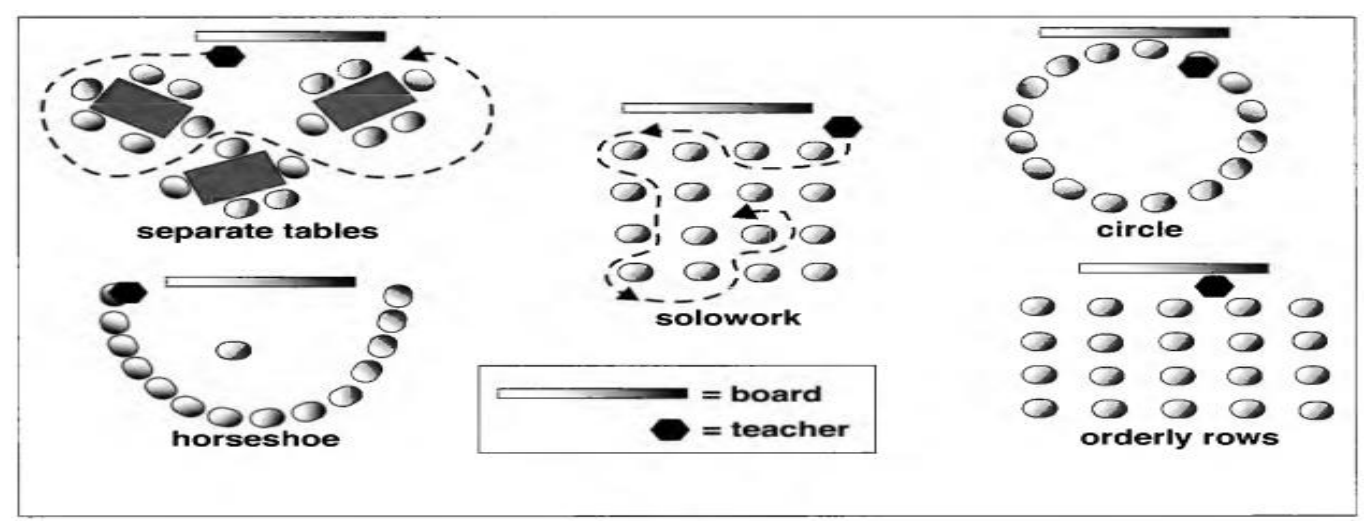

Fonte: HARMER (2007, p. 41) 
A figura 1 apresenta modelos de disposição utilizados em sala de aula, construídos a partir da posição do professor e do quadro. As mesas separadas apresentam-se como uma alternativa interessante para o trabalho em grupo, com espaço suficiente para o professor circular pelo ambiente e, assim, tendo acesso a todos os alunos. A disposição para trabalho individual possibilita que os alunos trabalhem por conta própria, mas ainda permite que o docente caminhe pela sala. Ambas as disposições em círculo e ferradura potencializam as discussões que podem ser realizadas em sala de aula, enquanto a disposição tradicional em linhas é mais adequada para uma aula expositiva.

Outro ponto importante é que, quando o professor se coloca na mesma posição dos alunos, os estudantes passam a se sentir mais inclinados a participarem das aulas já que essa quebra da figura do professor enquanto detentor absoluto do conhecimento, substituída pelo papel do moderador, mostra aos estudantes que eles são pessoas passivas de serem ouvidas e que a sala de aula é um lugar de discussão e construção, não de exposição.

\section{Metodologia}

Nossa proposta constituiu-se em compreender a sala de aula no contexto NucLi IsF/UFLA enquanto um sistema complexo e, dessa forma, buscar estratégias para aprimorar o ensino-aprendizagem nesse contexto. Para tanto, realizamos entrevistas semiestruturadas com alunos que estavam matriculados nos cursos de inglês de Interações Cotidianas e de Debates voltados para o público de níveis A1 e B2, respectivamente, de acordo com o Common European Framework of Reference for Languages ${ }^{2}$ (CEFR), e que contavam com experiência prévia em outros cursos de inglês.

O CEFR preconiza uma Abordagem Comunicativa e essa foi a escolhida pelos professores para condução das aulas, as quais se dão de modo interativo e dialógico, nos cursos do NucLi/IsF já que a demanda dos cursos, de acordo com a experiência adquirida até o momento da pesquisa, é principalmente voltada para a oralidade.

Segundo Richards (2006),

O ensino comunicativo pode ser entendido como um conjunto de princípios sobre os objetivos do ensino de línguas, os tipos de atividades que melhor facilitam a aprendizagem e o papel dos professores e dos estudantes na sala de aula. (p. 02)

\footnotetext{
${ }^{2}$ Quadro Comum Europeu de Referência para Línguas (QCER)
} 
Acreditamos que tal abordagem se apresenta como uma boa alternativa para ensino de línguas já que oferece aulas interativas, as quais se harmonizam com a Teoria da Complexidade. A referida abordagem coloca os alunos como centro de processo de ensino e aprendizagem o que possibilita que suas múltiplas identidades e competências possam ser valorizadas pelo professor que torna-se um mediador dessas interações ao invés de "transmissor" do conhecimento como acreditava-se , algumas décadas atrás.

A partir das entrevistas e com base nas experiências prévias e nos cursos ofertados pelo NucLi IsF a esses estudantes, busca-se entender quais aspectos ao longo das aulas influenciam o processo de ensino-aprendizagem. As perguntas presentes nas entrevistas foram desenvolvidas e organizadas em duas frentes: a primeira frente compreende questões sobre a experiência dos estudantes no que tange cursos de inglês realizados anteriormente aos cursos oferecidos pelo NucLi IsF e a segunda trata sobre as aulas desenvolvidas, no mesmo idioma, ao longo dos cursos oferecidos pelo NucLi IsF.

\section{Resultados e Discussão}

As entrevistas realizadas tinham como objetivo compreender as experiências prévias dos alunos em cursos de inglês anteriores a suas experiências no IsF assim como contrastar isso com a experiência atual no programa, levando em consideração a sala de aula como sistema complexo. As entrevistas foram aplicadas ao final do curso de forma oral, gravadas, transcritas e posteriormente analisadas à luz da Metodologia de Pesquisa Qualitativa.

Seguem abaixo, divididas em dois blocos, as perguntas abertas utilizadas nas entrevistas:

Bloco I - Perguntas sobre a experiência dos estudantes no que tange cursos de inglês realizados anteriormente aos cursos do NucLi IsF

- Como foi sua experiência nos cursos anteriores ao NucLi?

- Como era a interação entre professores e estudantes?

- Como era a organização física das salas?

- Você costumava fazer trabalhos em grupos ou duplas?

Bloco II - Perguntas sobre as aulas desenvolvidas ao longo dos cursos de inglês oferecidos pelo NucLi IsF

- No que as aulas divergiram de suas expectativas? 
- Como foi a interação entre professor e estudantes e como se deu a organização física da sala?

- Você acha que a organização da sala afetou sua aprendizagem? Como?

- Você acha que trabalhos em dupla e/ou em grupos são boas estratégias para o processo de ensino-aprendizagem em inglês? Como isso afetou seu desenvolvimento?

- Com base nas experiências vivenciadas ao longo dos cursos do IsF, houve alguma mudança em como você enxerga o ensino de inglês? Se sim, qual/quais?

Conforme afirma Flick (2008), citado por Rosa, Monteiro e Nascimento Junior (2019), a pesquisa de caráter qualitativo tem como característica a apropriação de perspectivas dos participantes e reflexividade do pesquisador. Nesse sentido, ela permite uma aproximação significativa com o objeto de estudo.

Após transcrição das entrevistas, as mesmas foram analisadas a partir da categorização, derivada da análise de conteúdo (MINAYO, 2002).

Para que a identidade dos participantes seja preservada, eles serão referidos como "E” e em seguida um número para os diferenciar entre si (Ex. E1, E2, E3). Segue abaixo a transcrição de fragmentos de algumas falas das entrevistas e quadro com as categorias, descrição e frequência:

E1 - Às vezes um perguntava para o outro 'Como fala isso?' e a gente ia se ajudando.

E2 - Eu tenho certeza que a maneira como eu tive todas as minhas aulas é a melhor maneira.

E3 - É uma forma menos exaustiva de aprender o idioma.

E4 - O quê que fulano vai pensar se eu for mal?

E5 - Eu acho que professor muito fechado prejudica o aprendizado.

E6 - Todo mundo parece disposto a colaborar com os outros.

E7 - Toda experiência, por mais que os métodos sejam os mesmos, acaba sendo diferente.

E8 - Porque nos aproxima da vivência, fica muito mais fácil aprender quando se prática de forma natural, como querendo ou não fazemos. Estar em um meio que de alguma forma traz a 'cultura' de outro local e misturar isso facilita o aprendizado. Tipo um intercâmbio, quando a gente está totalmente imerso naquela cultura seremos 'obrigados' a aprender. 
E9 - Interação, tratar o outro de igual pra igual... fazer grupos, duplas, sempre diferentes. Tornar o ambiente íntimo, familiar, amigável.

E10 - Fiz anos de curso particular, mas me sentia intimidado porque meus colegas eram mais novos e aprendiam mais rápido.

E11 - Acho que o círculo funciona bem porque nos força a olhar para a cara um do outro e a conversar entre a gente e isso ajuda na criação de um laço com o outro até fora da sala, mas, por outro lado, uma pessoa tímida fica mais tímida.

E12 - Tive uma maior facilidade para aprender quando tinha um contato maior com meus colegas de classe, semestre passado. Esse semestre é todo mundo quietinho e isso me deixa mais tímido.

E13 - Antes do IsF, tive que lidar com um professor que bufava quando eu fazia alguma pergunta que ele achava que era "estúpida". Acabou prejudicando.

E14 - Por ter uma relação maior, me esforço para não desapontar a professora. E15 - Éramos próximos na minha turma e isso me deixava mais confortável. Era todo mundo na mesma idade e com dificuldades parecidas.

E16 - A nossa sala era um grupo grande, lembra? Sempre fazíamos um semicírculo [sic]e íamos conversando sobre o tema da aula, a professora ia esclarecendo dúvidas e nós, alunos, íamos discutindo um com o outro.

E17 - Não gosto de gente que se acha melhor que os outros. Não funciona.

Quadro 1 - Categorias, descrição e frequência das falas dos estudantes.

\begin{tabular}{|l|l|c|}
\hline Categorias & Descrição & Frequência \\
\hline $\begin{array}{l}\text { Interação professor-aluno } \\
\text { e aluno-aluno }\end{array}$ & $\begin{array}{l}\text { Essa categoria abriga as falas que } \\
\text { ressaltam como as interações que ocorrem } \\
\text { nas aulas influenciam o processo de } \\
\text { ensino-aprendizagem. }\end{array}$ & 16 \\
\hline Organização da sala & $\begin{array}{l}\text { Aqui foi possível agrupar falas que } \\
\text { consideram a forma como a sala de aula se } \\
\text { organiza ressaltando sua atuação no } \\
\text { processo de ensino-aprendizagem. }\end{array}$ & 7 \\
\hline
\end{tabular}

Fonte: Elaborado pelos autores, 2019.

Alguns estudantes relataram suas experiências anteriores como algo intimidante, no caso de escola de idiomas, devido à sensação de incapacidade que a falta de nivelamento causou, e, individualista, no caso da aula particular individual. Ao serem questionados acerca de determinado comportamento do professor em sala de aula, os entrevistados indicaram que o humor do mediador interfere diretamente na resposta da turma. 
Foi possível perceber que fora do contexto do IsF há uma busca nas aulas de língua em geral pela interatividade. Os estudantes demonstraram um maior interesse em aulas dinâmicas com professores interativos e abertos à conversa. Segundo Smolka e Góes (1995), a elaboração cognitiva estabelecida entre indivíduo e objeto de conhecimento é diretamente influenciada pela relação que o indivíduo tem com os outros sujeitos inseridos naquele ambiente. Logo, uma boa relação com o professor e demais alunos cria um ambiente aberto à comunicação e à construção de aprendizado.

Os estudantes relataram que um senso de comunidade foi criado dentro da sala de aula. Esse processo ilustra o que Wenger (2011) nomeia comunidade de prática. Tal comunidade referencia um ambiente no qual um grupo de pessoas possui um objetivo de aprendizagem comum e buscam melhores formas de alcançá-lo enquanto interagem entre si. A respeito disso, Tassoni (2000) apresenta que a interação entre pessoas influencia diretamente na construção de aprendizado:

Considerando que o processo de aprendizagem ocorre em decorrência de interações sucessivas entre as pessoas, a partir de uma relação vincular, é, portanto, através do outro que o indivíduo adquire novas formas de pensar e agir e, dessa forma apropria-se (ou constrói) novos conhecimentos. (TASSONI, 2000, p. 06)

Essa aproximação entre sujeitos pode ser promovida pelo professor-mediador, conforme já apontado por Harmer (2007). Nesse caso, o mediador, ao optar pelo trabalho em grupo ou duplas, promove, imediatamente, a interação entre os estudantes. Diante das questões apresentadas pelos estudantes em seus questionários, foi possível verificar que esse tipo de abordagem gera nos alunos tanto motivação quando promove o aprendizado.

É importante ressaltar, no entanto, mais uma vez, que um sistema complexo se caracteriza pela multiplicidade de elementos e a relação não-hierárquica e não-linear entre eles. Segundo Guimarães, Dourado e Santiago, “O efeito de uma ação em um sistema não linear pode acarretar uma reação totalmente diferente do planejado, pode seguir rumos jamais esperados" (GUIMARÃES, DOURADO, SANTIAGO, 2016, p. 05). Assim, cada pequena alteração trará modificações ao sistema e não há como serem previstas, devido sua natureza caótica. A respeito dessa afirmação, Silva (2008) diz que "um sistema verdadeiramente caótico apresenta, em determinado momento, uma ordem, porém, a interação entre os elementos que conformam o sistema é tamanha, que se cria uma desordem, que, por seu turno, fará emergir uma nova ordem” e, assim, traz que é da 
desordem que nasce uma nova ordem e que a caoticidade de um sistema é o que o torna adaptativo.

\section{Considerações finais}

A natureza caótica dos sistemas complexos, em um contexto de sala de aula, potencializa as diferentes estratégias que o professor pode usar na sala de aula. Devemos entender que cada turma de estudantes é única e incomparável, o que funciona com um grupo pode não funcionar com outro. Todas as pessoas dentro da sala são humanas sujeitas a erros e emoções e, para além disso, cada ambiente escolar será influenciado por sua estrutura, que pode ou não beneficiar o processo de ensino/aprendizado.

A forma como foi organizado o espaço físico das aulas e a promoção de atividades em grupos e duplas contribuiu para a criação de uma comunidade nas salas observadas e entrevistadas dentro do NucLi/IsF, pois os alunos ajudaram-se mutuamente auxiliando no processo de ensino-aprendizado e descreveram a experiência positivamente. Também a forma como os professores comportaram-se nesse ambiente pôde colaborar para uma melhor conexão com o aluno, gerando engajamento e também favorecendo ao aprendizado.

Vale ressaltar a relevância de estudos nessa linha serem feitos e levados para dentro de uma sala de aula de formação de professores, a fim de promover reflexão e proporcionar uma tomada de consciência na prática docente não somente em salas de ensino superior, como também em ensino médio e básico.

\section{Referências Bibliográficas}

CAMERON, L.; LARSEN-FREEMAN, D. Complex systems and applied linguistics. International journal of applied linguistics, v. 17, n. 2, p. 226-239, 2007.

FLICK, U. Introdução à pesquisa qualitativa. Artmed editora, 2008.

FREIRE, P. Carta de Paulo Freire aos professores. Estudos Avançados, 15(42), 259-268. 2001.

GUIMARÃES, J.; DOURAdO, M.; SANTIAGO, R. C. A Complexidade da Sala de Aula. Artefactum - Revista de estudos em linguagem e tecnologia, 2016.

HARMER, J. How to teach English: new edition. Harlow: Pearson Education Limited, 2007. 
LEFFA, V. J. ReVEL na Escola: Ensinando a língua como um sistema adaptativo complexo. ReVEL, v.14, n. 27, 2016.

LIMA, J. S.; A complexidade da prática docente na complexidade da educação. In: XIII Congresso Nacional de Educação, EDUCERE, 2017.

MANDELBROT, B. B. (1982). The fractal geometry of nature. W.H. Freeman and Company.

MINAYO, M. C. S.(Org.). Pesquisa social: teoria, método e criatividade. 21. Ed. Petrópolis/RJ: Vorazes, 2002.

MORIN, E. Introdução ao pensamento complexo. Porto Alegre: Sulina, 2007.

RICHARDS, J. C. Communicative Language Teaching Today.Cambridge: Cambridge University Press, 2006

RIOS NETO, A. S. Complexidade nas organizações / Antônio Sales Rios Neto. In: Suffragium: revista do Tribunal Regional Eleitoral do Ceará, v. 4, n. 7, p. 49-57, jul./dez. 2008

ROSA, M. M. S; MONTEIRO, J. A. ; NASCIMENTO JUNIOR, A. F. . Políticas para a Saúde Pública e o Ambiente: o desfecho de uma sequência didática a partir da Metodologia da Problematização. In: XV FÓRUM AMBIENTAL DA ALTA PAULISTA, 2019, Online. Anais do Fórum Ambiental da Alta Paulista, 2019.

SADE, L. A. Complexity and identity reconstruction in second language acquisition. Symposium paper presented at AILA 2008 - 15th World Congress of 18 Applied Linguistics, Essen/Germany, 2008.

SILVA, V. A dinâmica caleidoscópica do processo de aprendizagem colaborativo no contexto virtual: um estudo na perspectiva da complexidade/caos. Tese (Doutorado em Linguística Aplicada) - Faculdade de Letras, Universidade Federal de Minas Gerais, Belo Horizonte, 2008.

SMOLKA, A. L. B. \& GÓES, M. C. (orgs.). A linguagem e o outro no espaço escolar: Vygotsky e a construção do conhecimento. São Paulo: Editora Papirus, 1995.

TASSONI, E. C. M. Afetividade e aprendizagem: A relação professor-aluno. Campinas: ANPED, 2000.

TEIXEIRA, M. T.; REIS, M. F. A Organização do Espaço em Sala de Aula e as Suas Implicações na Aprendizagem Cooperativa.Meta: Avaliação, [S.1.], v. 4, n. 11, p. 162-187. 2012.

VAN LIER, L. Interaction in the language curriculum: Awareness, Autonomy, and Authenticity. London: Longman, 1996. 
VAN VELZEN, W. G. Making school improvement work: A conceptual guide to practice. Acco, 1985.

WENGER, E. Communities of practice: A brief introduction. Cambridge, UK: Cambridge University. 2011. 